\title{
A study of effects of anemia on maternal and perinatal outcomes
}

\author{
Som Prakash, Meenakshi Kandoria*, Anita Pal \\ Department of Obstetrics and Gynecology, KNSHM and C, IGMC, Shimla, Himachal Pradesh, India
}

Received: 18 April 2018

Accepted: 23 May 2018

\section{*Correspondence:}

Dr. Meenakshi Kandoria,

E-mail: mekandoria@gmail.com

Copyright: $\odot$ the author(s), publisher and licensee Medip Academy. This is an open-access article distributed under the terms of the Creative Commons Attribution Non-Commercial License, which permits unrestricted non-commercial use, distribution, and reproduction in any medium, provided the original work is properly cited.

\begin{abstract}
Background: The objective of the study was to evaluate the prevalence of anemia in antenatal women and to assess the effects of anemia on maternal and perinatal outcomes.

Methods: A cross sectional observational study was conducted on 1000 random patients admitted in the labour room. Results: Anemia was found in 687 patients (68.7\%) at the time of delivery. Nearly 321 (46.72\%) had mild, 349 $(50.80 \%)$ had moderate and $17(2.47 \%)$ had severe anemia. About $72 \%$ subjects were from $20-30$ years age group, $77.7 \%$ belonged to rural area, $87.8 \%$ were, booked cases. A total of $81 \%$ had received iron folic acid prophylaxis, $63.2 \%$, belonged to lower socioeconomic class, $91.2 \%$ were educated upto primary school and $47.7 \%$ were primigravida There were significant differences in prematurity, birth weight and hypertensive disorders of pregnancy between anemic and non anemic groups. About $20.4 \%$ of anemic patients had complications like Intra uterine growth retardation (IUGR), gestational hypertension, preeclampsia, eclampsia. Nearly $91.30 \%$ IUGR were anemic and all patients with preeclampsia, eclampsia and hemolysis elevated liver enzymes, and low platelet count (HELLP) syndrome had anemia. Low appearance, pulse, grimace, activity, and respiration (APGAR) score and increased incidence of admission to Neonatal Intensive Care Unit was seen in babies born to anemic mothers.

Conclusions: Maternal anaemia is associated with increased risks of postpartum haemorrhage, low birthweight, small-for-gestational age babies and perinatal death. While the best approach is prevention, a large number of women present with severe anaemia late in pregnancy. Since there is no clear guidance on how these women should be managed during labour and delivery, therefore, this issue needs to be addressed urgently.
\end{abstract}

Keywords: Anemia, Antenatal visits, Pregnancy outcomes

\section{INTRODUCTION}

Anemia is the most common nutritional deficiency disorder in the world. WHO has estimated that prevalence of anemia in pregnant women is 14 per cent in developed and $51 \%$ in developing countries and $65-75 \%$ in India. About one third of the global population (over 2 billion) is anaemic. ${ }^{1}$

Prevalence of anemia in all the groups is higher in India as compared to the developing countries. WHO estimates that even among South Asian countries, India has the highest prevalence of anemia. What is even more important is the fact that about half of the global maternal deaths due to anemia occur in South Asian countries; India contributes to about $80 \%$ of the maternal deaths due to anemia in South Asia. It is obvious that India's contribution both to the prevalence of anemia in pregnancy and maternal deaths due to anemia is higher than warranted by the size of its population. ${ }^{1}$

Anaemia is a condition in which the number of red blood cells (Anemia consequently their oxygen-carrying capacity) is insufficient to meet the body's physiologic needs. Specific physiologic needs vary with a person's age, gender, residential elevation above sea level (altitude), smoking behavior, and different stages of pregnancy. ${ }^{2}$ 
Anemia in pregnancy is defined as a hemoglobin concentration $<11.0 \mathrm{~g} / \mathrm{dl}$ or $<10.5 \mathrm{~g} / \mathrm{dl}$ in the second half of pregnancy. ${ }^{2}$

\section{Classification of anemia according to WHO/ICMR., ${ }^{2,3}$}

- Mild anemia - Hemoglobin concentration 10- 10.9 gm\%.

- Moderate anemia - Hemoglobin concentration 7$9.9 \mathrm{gm} \%$.

- Severe anemia - Hemoglobin concentration <7 $\mathrm{gm} / \mathrm{dl}$.

In view of the above, present study was carried out to find the prevalence of anemia and socio-demographic factors associated with anemia in pregnancy.

Women with mild anemia may go through pregnancy and labour without any adverse consequences. Women with moderate anemia are more susceptible to infections and recovery from infections may be prolonged. Premature births, low birth weight and perinatal mortality is higher. Substantial proportion of maternal deaths due to antepartum and post-partum hemorrhage, pregnancy induced hypertension and sepsis occur in women with moderate anemia. Severe anemia may present with circulatory failure if untreated it leads to pulmonary edema and death and even a minor blood loss may produce shock and death. Anemia directly causes 20 per cent of maternal deaths in India and indirectly accounts for another 20 per cent of maternal deaths. ${ }^{1}$

\section{Fetal consequences of anemia}

Studies to define the effect of maternal anemia on the fetus indicate that different types of decomposition occur with varying degrees of anemia. Most of the studies suggest that a fall in maternal hemoglobin below 11.0 $\mathrm{g} / \mathrm{d} 1$ is associated with a significant rise in perinatal mortality rate. There is usually a 2 to 3 -fold increase in perinatal mortality rate when maternal hemoglobin levels fall below $8.0 \mathrm{~g} / \mathrm{d} 1$ and 8-10 fold increase when maternal hemoglobin levels fall below $5.0 \mathrm{~g} / \mathrm{dl}$. A significant fall in birth weight due to increase inprematurity rate and intrauterine growth retardation has been reported when maternal hemoglobin levels were below $8.0 \mathrm{~g} / \mathrm{dl} .{ }^{1}$

\section{METHODS}

A cross sectional study was conducted in the Department of Obstetrics and Gynaecology, Kamla Nehru State Hospital for Mother and Child, Indira Gandhi Medical College, Shimla with effect from $1^{\text {st }}$ August 2015to $31^{\text {st }}$ July 2016. The study included 1000 random patients admitted in the labour room.

\section{Inclusion criteria}

Inclusion criteria were period Of Gestation $\geq 28$ weeks; singleton pregnancy.

\section{Exclusion criteria}

Exclusion criteria were babies born with major congenital anomalies, syndrome complexes; women with history of smoking, tobacco use, alcoholics, narcotic drug intake; women with medical illness like diabetes mellitus, heart disease and renal diseases, chronic HTN, gastrointestinal disease, hemolytic anemias, blood transfusion or any other chronic illness; TORCH infection, malaria during antenatal period; twin pregnancy; bleeding disorders and antepartum hemorrhage.

All cases were studied in full details regarding age, parity, literacy, occupation, diet, addiction and socioeconomic status. Total number of family members and status of family whether joint or nuclear family. The socio-economic class was determined according to the Modified Kuppuswamy's scale. Detailed history of present pregnancy with special reference to iron folic acid prophylaxis., detailed general physical examination, systemic and obstetric examination was done Maternal blood sample was taken for investigations. Detailed labour events and parameters of baby was recorded.

\section{RESULTS}

The present study was conducted on 1000 subjects admitted in labor ward, Kamla Nehru State Hospital for Mother and Child, Indira Gandhi Medical College, Shimla. Out of 1000 subjects, $313(31.3 \%)$ were non anemic and $687(68.7 \%)$ were anemic. Out of 687 anemic subjects, $321(46.72 \%)$ had mild, 349(50.80\%) had moderate and $17(2.47 \%)$ had severe anemia (Table 1$)$.

Out of $878(87.7 \%)$ booked subjects, $573(65.26 \%)$ had anemia, Out of 122 unbooked subjects, 114(93.44\%) had anemia. Most of the unbooked patients were anemic and about $11(64.71 \%)$ of severe anemia subjects were unbooked (Table 2).

In present study, majority of the subjects were from 2030 years age group (72\%), Significantly more proportion of anemia was seen among teenage subjects $(83.10 \%)$ with $11.86 \%$ of anemic teenage subjects having severe anemia, Most of the subjects belonged to the age group 20-30 years, this is the main reproductive age group in our population (Table 3 ).

In study population, $810(81 \%)$ subjects had received iron folic acid prophylaxis. Out of 810 subjects, who had received iron folic acid prophylaxis, 297 (36.67\%) were non anemic and $513(63.33 \%)$ had anemia. Out of 513 anemic subjects, 268 (52.24\%) had mild, 239 (46.59\%) had moderate, and $6(1.17 \%)$ had severe anemia. Out of 190 subjects, who had not received iron folic acid prophylaxis, $16(8.24 \%)$ were non anemic and 174 $(91.58 \%)$ were anemic. Out of 174 anemic subjects, 53 $(30.46 \%)$ had mild, $110(63.22 \%)$ had moderate and 11 $(6.32 \%)$ had severe anemia (Table 4$)$. 
Table 1: Distribution of patients according to anemia status.

\begin{tabular}{|lllll|}
\hline Non Anemic (313) & Anemic ( 687) & & & \\
\hline \multirow{2}{*}{$313(31.3 \%)$} & Mild anemia & Moderate anemia & Severe anemia & Total \\
\cline { 2 - 4 } & $321(46.72 \%)$ & $349(50.80 \%)$ & $17(2.47 \%)$ & $687(68.7 \%)$ \\
\hline
\end{tabular}

Table 2: Distribution of anemic patients according to booked status.

\begin{tabular}{|llllll|}
\hline Type of admission & Non anemic (313) & Anemic (687) & Mild (321) & Moderate (349) & Severe (17) \\
\hline Booked $878(87.8 \%)$ & $305(34.74)$ & $573(65.26 \%)$ & $286(49.91 \%)$ & $281(49.04 \%)$ & $6(1.05 \%)$ \\
\hline Unbooked $122(12.2 \%)$ & $8(6.56 \%)$ & $114(93.44 \%)$ & $35(30.70 \%)$ & $68(59.65 \%)$ & $11(9.65 \%)$ \\
\hline
\end{tabular}

Table 3: Age group comparison of study subjects in similar other studies.

\begin{tabular}{|lllllllll|}
\hline Age (years) & Virender et al (114) & \multicolumn{2}{l|}{ Pankaj Kumar et al } & Malkar et al (400) & \multicolumn{2}{l|}{$\begin{array}{l}\text { Present study 2015-16 } \\
(1000)\end{array}$} \\
& $\begin{array}{l}\text { Non anemic Anemic } \\
(\%)\end{array}$ & $\begin{array}{l}\text { Non Anemic } \\
(\%)\end{array}$ & $\begin{array}{l}\text { Anemic } \\
(\%)\end{array}$ & $\begin{array}{l}\text { Non Anemic } \\
(\%)\end{array}$ & $\begin{array}{l}\text { Anemic } \\
(\%)\end{array}$ & $\begin{array}{l}\text { Non } \\
\text { Anemic }(\%)\end{array}$ & $\begin{array}{l}\text { Anemic } \\
(\%)\end{array}$ \\
\hline$\leq 19$ & 0.00 & 100 & 9.1 & 90.91 & 2.4 & 97.6 & 16.90 & 83.10 \\
\hline $20-24$ & 4.7 & 95.3 & 37.93 & 62.07 & 6.9 & 93.1 & 31.78 & 68.22 \\
\hline $25-29$ & 4.2 & 95.8 & 96.15 & 3.85 & 8.8 & 91.2 & 31.83 & 68.17 \\
\hline $30-34$ & 0.00 & 100 & 21.05 & 78.95 & 12 & 88 & 34.48 & 65.52 \\
\hline$\geq 35$ & -- & -- & 100 & 0.00 & 6.25 & 93.75 & 34.37 & 65.63 \\
\hline
\end{tabular}

Table 4: Distribution of anemia in study subjects according to iron and folic acid prophylaxis.

\begin{tabular}{|llllll|}
\hline $\begin{array}{l}\text { Iron Folic Acid } \\
\text { Prophylaxis }(\mathbf{1 0 0 0})\end{array}$ & $\begin{array}{l}\text { Non Anemic (313) } \\
(\%)\end{array}$ & $\begin{array}{l}\text { Anemic (687) } \\
(\%)\end{array}$ & $\begin{array}{l}\text { Mild (321) } \\
(\%)\end{array}$ & $\begin{array}{l}\text { Moderate (349) } \\
(\%)\end{array}$ & Severe (17) $(\%)$ \\
\hline Received 810, (81\%) & $297(36.67)$ & $513(63.33)$ & $268(52.24)$ & $239(46.59)$ & $6(1.17)$ \\
\hline $\begin{array}{l}\text { Not received } 190 \\
(19 \%)\end{array}$ & $16(8.42)$ & $174(91.58)$ & $53(30.46)$ & $110(63.22)$ & $11(6.32)$ \\
\hline
\end{tabular}

Table 5: Maternal complications in anemic and non anaemic study subjects.

\begin{tabular}{|c|c|c|c|c|c|c|}
\hline $\begin{array}{l}\text { Maternal complications } \\
(\mathbf{1 0 0 0 )}\end{array}$ & $\begin{array}{l}\text { Non anemic } \\
(313)(\%)\end{array}$ & $\begin{array}{l}\text { Anemic } \\
(n=687)(\%)\end{array}$ & $\begin{array}{l}\text { Mild } \\
(321)(\%)\end{array}$ & $\begin{array}{l}\text { Moderate } \\
(349)(\%)\end{array}$ & $\begin{array}{l}\text { Severe } \\
(17)(\%)\end{array}$ & $\mathbf{P}$ value \\
\hline None $796(79.6 \%)$ & $275(34.55)$ & $521(65.45)$ & $261(50.10)$ & $257(49.32)$ & $3(0.58)$ & \\
\hline $\begin{array}{l}\text { Gestational hypertension } \\
54(5.4 \%)\end{array}$ & $21(38.89)$ & $33(61.11)$ & $16(48.48)$ & $17(51.52)$ & 0 & 0.27 \\
\hline Iugr $46(4.6 \%)$ & & $42(91.30)$ & $16(38.10)$ & $23(54.76)$ & $3(7.14)$ & $<0.01$ \\
\hline Pre Eclempsia $34(3.4 \%)$ & 0 & $34(100)$ & $14(41.18$ & $16(47.06)$ & $4(11.76)$ & $<0.01$ \\
\hline Prom $30(3 \%)$ & $9(30)$ & $21(70)$ & 0 & $21(100)$ & & 1.00 \\
\hline Pprom $27(2.7 \%)$ & $4(14.81)$ & $23(85.19)$ & $8(34.78)$ & $15(65.22)$ & 0 & 0.096 \\
\hline Hellp syndrome $6(0.6 \%)$ & 0 & $6(100)$ & $6(100)$ & 0 & 0 & 0.22 \\
\hline Eclempsia 4 (0.4\%) & 0 & $4(100)$ & 0 & 0 & $4(100)$ & 0.416 \\
\hline $\operatorname{Ccf} 2(0.2 \%)$ & 0 & $2(100)$ & 0 & 0 & $2(100)$ & 0.847 \\
\hline $\begin{array}{l}\text { Pulmonary Edema } 1 \\
(0.1 \%)\end{array}$ & 0 & $1(100)$ & 0 & 0 & $1(100)$ & 1.00 \\
\hline
\end{tabular}

In study group, $204(20.4 \%)$ had complications, out of which, 54(5.4\%) had gestational hypertension out of which $21(38.89 \%)$ had no anemia and $33(66.11 \%)$ were anemic. Nearly $46(4.6 \%)$ had IUGR, out of which 4 $(8.70 \%)$ were non anemic and $42(91.30 \%)$ were anemic. $34(3.4 \%)$ had pre eclempsia and all $34(100 \%)$ were anemic. About 30 (3\%) had PROM $9(30 \%)$ were non anemic and 21(70\%) were anemic, 27 (2.7\%) had
PPROM 4 (14.81\%) were non anemic and $23(85.19 \%)$ had anemia, $6(0.6 \%)$ had HELLP syndrome all $6(100 \%)$ had mild anemia. $4(0.4 \%)$ had eclempsia, $2(0.2 \%)$ had CCF and $1(0.1 \%)$ had pulmonary edema all had anemia. This table shows that IUGR and pre eclempsia has significant correlation with anemia having $\mathrm{p}$ value $<0.001$ and rest of the complications doesn't have any direct 
correlation. Severe anemia had grave complications like CCF and pulmonary edema (Table 5).

Birthweight of babies distributed in relation to severity of anemia, out of 1000 subjects,47 (4.7\%) had babies weigh between $1-1.5 \mathrm{~kg}, 2$ (4.26\%)were born to non anemic mothers, 45 babies born to anemic mothers. 57 (5.7\%) between $(1.6-2 \mathrm{~kg}), 4(7.02 \%)$ were born to non anemic and 53(92.98\%)were born to anemic mothers 165 $(16.5 \%)$ subjects weigh between $(2.1-2.4 \mathrm{~kg}), 37$ $(24.42 \%)$ were born to non anemic and $128(75.58 \%)$ were born to anemic mothers and 731(73.1\%)subjects had babies weighing $\geq 2.5 \mathrm{~kg}, 270$ (36.94\%) were born to non anemic and 461(63.06\%)were born to anemic mothers. This table shows linear relationship between anemia and low birth weight with a significant $p$ value of $<0.001$, as majority of the babies with low birth weight are born to anemic mothers. It was observed that anemic subjects had significantly high number of preterm births $(89.56 \%)$, low birth weight $(84.01 \%)$, low APGAR score at 1 minute $(82.84 \%)$ and 5 minute $(96.61 \%)$, admission to NICU $(96.77 \%)$ and all neonatal deaths, maternal anemia had a significant correlation with $\mathrm{p}$ value of $<0.001$ and outcome worsened with severity of anemia (Table 6).

Table 6: Perinatal complications in anemic and non anaemic study subjects.

\begin{tabular}{|c|c|c|c|c|c|c|}
\hline $\begin{array}{l}\text { Perinatal Complications } \\
\text { (1000) }\end{array}$ & $\begin{array}{l}\text { Non Anemic } \\
(313)\end{array}$ & $\begin{array}{l}\text { Anemic } \\
(687)\end{array}$ & $\begin{array}{l}\text { Mild } \\
(321)\end{array}$ & $\begin{array}{l}\text { Moderate } \\
(349)\end{array}$ & $\begin{array}{l}\text { Severe } \\
(17)\end{array}$ & P value \\
\hline Preterm 134 (13.4\%) & $14(10.44)$ & $120(89.56)$ & $55(45.83)$ & $51(42.50)$ & $14(10.44)$ & $<0.001$ \\
\hline Low birth weight 269 (26.9\%) & $43(15.98)$ & $226(84.01)$ & $89(39.38)$ & $120(53.10)$ & $17(7.52)$ & $<0.001$ \\
\hline $\begin{array}{l}\text { Apgar score at } 1 \mathrm{~min} \\
134(13.4 \%)\end{array}$ & $23(17.16)$ & 2.84) & $0.57)$ & $2.07)$ & $11(9.10)$ & $<0.001$ \\
\hline $\begin{array}{l}\text { Apgar score at } 5 \mathrm{~min} \\
61(6.1 \%)\end{array}$ & $2(3.39)$ & $59(96.61)$ & $21(35.59)$ & $28(47.46)$ & $10(16.95$ & $<0.001$ \\
\hline Shifted To Nicu 87 (8.7\%) & $28(32.18)$ & $59(67.82)$ & $20(33.90)$ & $39(66.10)$ & $0(0)$ & 0.88 \\
\hline Admission To Nicu 62 (6.2\%) & $2(3.23)$ & $60(96.77)$ & $19(31.67)$ & $32(53.33)$ & $9(15.00)$ & $<0.001$ \\
\hline Neonatal death $8(0.8 \%)$ & $0(0)$ & $8(100)$ & $0(0)$ & $3(37.5)$ & $5(62.5)$ & 0.10 \\
\hline
\end{tabular}

The perinatal outcome distributed in relation the anemia, $87(8.7 \%)$ babies were shifted to NICU, 62 (6.2\%) got admission to NICU and $8(0.8 \%)$ babies died during perinatal period. Out of 87 babies who got shifted to NICU, $28(32.18 \%)$ were born to non anemic and $59(67.82 \%)$ were born to anemic mothers. Out of 62 babies, who got admission to NICU. 2 (3.23\%) were born to non anemic and $60(96.77 \%)$ were born to anemic mothers. Out of 60 babies, $19(31.67 \%)$ were born to mild, $32(53.33 \%)$ moderate and $9(15 \%)$ to severely anemic mothers. Out of 8 neonatal deaths, no baby were born to non anemic and all $8(100 \%)$ were born to anemic mothers.

\section{DISCUSSION}

Present study showed that $68.7 \%$ of the antenatal women are anemic and similar results were shown by Nair et al and NFHS India $(58.7 \%)$. $^{4,5}$ Anemia was seen among teenage subjects $(83.10 \%)$ with $11.86 \%$ of anemic teenage subjects having severe anemia, Virender et al found $100 \%$ anemia in teenager pregnancy which is $83.10 \%$ in our study. ${ }^{6}$ Similar in case of study conducted by Malkar et al is from Assam, where prevalence of anemia is significantly high as compared to Himachal. ${ }^{7}$ Anemia among teenagers may be due to growing age and ignorance, teenagers do not have antenatal care and do not take iron folic acid prophylaxis. Youngest subject was 18 years and oldest was 40 years old. Severe anemia was highest among teenagers. Most of the subjects belonged to the age group 20-30 years, this is the main reproductive age group in our population. Similarly, in our study $93.44 \%$ of unbooked patients are anemic, which is comparable to studies conducted by RenuBedi et al. ${ }^{8}$ As in our population most of the unbooked patients were from rural areas and migrant population. They were not having routine antenatal checkups, not taking IFA prophylaxis and belonged to low socioeconomic background. In present study, prevalence of anemia was increasing with gravidity and most affected groups were fourth gravida $(88.14 \%)$ and grand multipara $(80.77 \%)$. Similarly trends were shown by studies conducted by Manjulatha et al and Sharma et al. ${ }^{9,10}$ Manjulatha et al has conducted their study in Andhra pradesh where prevalence of anemia is higher and Sharma et al has conducted their study on urban population of Jankapuri, Nepal. ${ }^{9,10}$

Anemia is associated with increased incidence of preterm delivery $(89.59 \%)$ which is correlating with studies conducted by Lone et al (79.8\%), Bakhtiar et al (77.5\%), Karasahin et al $(76 \%)$ and Renu Bedi et al (92.9\%)..$^{8,11-13}$ $91.3 \%$ of IUGR babies were born to anemic mothers, which is correlating with study conducted by Renu Bedi 
et al $(96.3 \%)$. Similar results were found by Lone et al $(69.5 \%)$, Bakhtiar et al $(63 \%)$ and Karasahin et al $(66.7 \%)$. Incidence of pre eclempsia $(100 \%)$ was higher in our study, as compared to studies conducted by Taner et al (65.2\%) and Karasahin et al (73.7\%). All studies had significantly higher number of anemic subjects having pre eclempsia, which suggest a linear relationship of anemia with pre eclempsia. Anemia is associated with low birth weight babies, as $80.01 \%$ of low birth weight babies were born to anemic mothers, similar observation was seen in studies conducted by Renu Bedi et al (96.1\%), Bakhtiar et al $(65.1 \%)$ and Lone et al $(68.8 \%)$. Anemia is associated with increased incidence of fetal distress which is shown in present study, as babies having low APGAR score at one minute $(82.84 \%)$ and five minutes $(96.72 \%)$ were born to anemic mothers, which is higher than as observed by Lone et al (66.7\%) and Bakhtiar et al $(63.6 \%)$, but all studies had significantly higher number of subjects from anemic group with fetal distress. Most of the babies requiring admission to NICU were born to anemic mothers and similar results were observed by Karasahin et al. 8 neonatal deaths observed in perinatal period, all neonates were born to anemic i.e. $100 \%$. Similar high percentages were found by Lone et al $(75 \%)$ and Bakhtiar et al $(77.8 \%)$. Present study also had increased incidence of gestational hypertension, PPROM, PROM, eclempsia, CCF and pulmonary edema in anemic subjects. Above table shows that anemia is associated with increased incidence of maternal and fetal complications and requires early detection and treatment. ${ }^{8,11-14}$

\section{CONCLUSION}

From present study it is concluded anemia has definite association between adverse maternal and poor perinatal outcomes. Anemia was found to have increased association with preterm labor, IUGR, pre-eclempsia, low birth weight babies, increased incidence of fetal distress, low APGAR score and increased incidence of admission to NICU and outcome worsens with severity. This signifies early detection and treatment of maternal anemia may help to reduce maternal and neonatal morbidity associated with anemia. In present study prevalence of anemia among study population was very high and maternal and perinatal morbidity increased with severity of anemia. Most affected population was of teenage mothers, migrant population, unbooked, those who had not received IFA prophylaxis, low socioeconomic class, laborers, subjects with inadequate food habits and multipara subjects. Strategies to control nutritional anemia in many developing countries, especially India, have so far not met with success. It has become apparent that administrative problems and health delivery system will have to be improved to combat anemia. Screening for anemia early in pregnancy and prompt treatment depending on cause and degree of anemia is essential.
Funding: No funding sources

Conflict of interest: None declared

Ethical approval: The study was approved by the Institutional Ethics Committee

\section{REFERENCES}

1. Kalaivani K. Prevalence and consequences of anemia in pregnancy. Indian J Med Res. 2009;130(5):627-33.

2. WHO. Haemoglobin concentration for the diagnosis of anaemia and assessment of severity. Geneva: World Health Organization; 2011.

3. Bivalkar NY, Wingkar KC, Joshi AG, Jagtap S. Assessment of severity \& types of anemia during pregnancy in rural population in western Maharashtra. Indian J Appl Mec Red. 2014;4(1):160-3.

4. Nair M, Choudhury MK, Choudhury SS, Kakoty SD, Sarma UC, Webster P, et al. Association between maternal anemia and pregnancy outcome:a cohart study in Assame India. BMJ Glob Health. 2016;26(1);1-10.

5. National Family Health Survey (NFHS-3) Pregnant women age 15-49 who are anemic.Key indicator of Himachal Pradesh. 2005-06.

6. Gautam VP, Bansal Y, Taneja DK, Saha R. Prevalence of anemia amongest pregnant women and its sociodemographics. Ind J Community Med. 2002;10(5):15761.

7. Malakar M. High prevalence of anemia in pregnant women of Lakhimpur District of Assam. Indian J Basic Appl Med Res. 2014;3(4):314-21.

8. Bedi R, Acharya R, Gupta R, Pawar S, Sharma R. Maternal factors of anemia in third trimester of pregnancy and its association with fetal outcome. Int Mul J Health. 2015;1(7):9-16.

9. Manjulatha B, Padmasri P, Prathibha Sravanthi TP. Prevalence of Anemia in pregnant Women in Tertiary Care Centre. ISRO J Dental Med Sci. 2015;14(7):91-5.

10. Sharma S, Yadav DP, Yadav RK, Prakash S, Yadav K. Prevalence and Medical correlates of Anemia in pregnant Women visiting Janaki Medical College. Int J Curr Res Med Sci. 2015;14(7):91-5.

11. Bakhtiar UJ, Khan Y, Nasar R. Relationship between maternal hemoglobin and Perinatal outcome. Rawal Med J. 2007;32(1):102-4

12. Karasahin E, Ceyhan ST, Goktolga U, keskin U, Baser I. Maternal Anemia and Parinatal Outcome. Turk J Gynecol Obstet Reprod Med. 2007;15(3):127-9

13. Lone FW, Qureshi RN, Emmanuel F. Maternal anaemia and its impact on perninatal outcome in a tertiary care hospital in Pakistan. Eastern Mediterranean Health J. 2004;6(10):801-7.

14. Taner CE, Ekin A, Solmaz U, Gezer C, Cetin B, Kelesoglu M, et al. Prevalance and risk factor of anemiaamong pregnant women attending high volume tertiary care centre for delivery. J Turk Ger Gynecol Assoc. 2015;16(6):231-7.

Cite this article as: Prakash S, Kandoria M, Pal A. A study of effects of anemia on maternal and perinatal outcomes. Int J Reprod Contracept Obstet Gynecol 2018;7:2719-23. 